\title{
The influence of manganese on kinetics of austenitization of the Fe-Mn-C ternary alloys
}

\author{
Lingnan Kong*, Yaohui Liu**, Yulai Song***, Jia'an Liu****,Shasha Li*****, \\ Yan Liang******, Yi Zheng*******, Wei Cui********* \\ * Key Laboratory of Automobile Materials of Ministry of Education \& School of Materials Science and Engineering, \\ Nanling Campus, Jilin University, Changchun 130025, China, E-mail: unhyde@163.com \\ **Jilin University, Nanling Campus, Changchun 130025, China, E-mail: lyh@jlu.edu.cn \\ ***Jilin University, Nanling Campus, Changchun 130025, China, E-mail: songyulai2005@163.com \\ ****Jilin University, Nanling Campus, Changchun 130025, China, E-mail: liuja@jlu.edu.cn \\ *****Jilin University, Nanling Campus, Changchun 130025, China, E-mail: 646279441@qq.com \\ ******Jilin University, Nanling Campus, Changchun 130025, China, E-mail: 794962382@qq.com \\ *******Jilin University, Nanling Campus, Changchun 130025, China, E-mail: 914944062@qq.com \\ ********Jilin University, Nanling Campus, Changchun 130025, China, E-mail: 705435007@qq.com \\ crossref http://dx.doi.org/10.5755/j01.mech.23.2.18111
}

\section{Introduction}

In order to achieve the expected structure and properties during the heat treatment process, most steels must first be heated to the austenite state and then cooled in an appropriate way. Generally, the transformation that occurs when the steal is heated is referred to as "austenization". The formation of austenite has an important influence on the mechanical properties: as the austenite grains become finer, and then the grains of the transformation product are finer after cooling. Also, the strength, plasticity and toughness are better, and vice versa. This is especially true in regards to the impact toughness, which decreased significantly $[1,2]$. Therefore, the research on the structure transformation of steel during heating can control and improve the heat treatment process in such a way that will change the structure of steel at high temperature conditions, as well as provide exploration to determine the full performance potential of the steel [3,4]. However, there is minimal information regarding the kinetics of austenite transformation as compared to the decomposition of austenite $[5,6]$.

There is a difference between the austenite formation and its decomposition. The composition, structure and temperature influence the austenite formation [7]. By studying the austenization kinetics of the low alloy steel during the spheroidizing process and the austenization process of martensite in $\mathrm{Fe}-\mathrm{C}-\mathrm{M}$ alloys, it was found that the diffusion of carbon may change through the introduction of alloying elements in steel $[8,9]$.

In this work, the influence of the Mn element on the austenization kinetics of the $\mathrm{Fe}-\mathrm{Mn}-\mathrm{C}$ ternary alloys is studied by comparing the experimental plots curves and the JMAK model under the continuous heating. The result should contribute to deeper understanding of the phase transformation of carbon steel.

\section{Experimental}

\subsection{Preparation of test specimens}

Four sets of $\mathrm{Fe}-\mathrm{Mn}-\mathrm{C}$ ingots were smelted by an intermediate frequency furnace. Then they were cast into a
Y-shaped sand mold and continuously cooled for 24 hours. In order to remove the oxygen in the liquid steel, small amounts of Al were introduced when the materials were completely melted. The amount of the steel is close to $5 \mathrm{~kg}$. The chemical composition is shown in Table 1.

Table 1

Chemical composition of the specimens (wt\%)

\begin{tabular}{|c|c|c|c|c|c|}
\hline & C & Mn & P & S & Fe \\
\hline 1\# & 0.98 & 0.99 & 0.03 & 0.02 & Bal. \\
\hline 2\# & 1.01 & 1.36 & 0.03 & 0.02 & Bal. \\
\hline 3\# & 0.99 & 2.18 & 0.04 & 0.03 & Bal. \\
\hline 4\# & 1.03 & 2.72 & 0.04 & 0.02 & Bal. \\
\hline
\end{tabular}

\subsection{DSC measurement}

In order to study the austenization process, a cylindrical specimen with a size of $\Phi 2.0 \times 0.5 \mathrm{~mm}$ was used to carry out the DSC investigations by a Netzsch DSC 404C. The specimens were heated from room temperature to $1373 \mathrm{~K}$ at $10 \mathrm{~K} / \mathrm{min}$ and then were cooled down to room temperature at $40 \mathrm{~K} / \mathrm{min}$. The whole test process was executed in a high pure flowing argon atmosphere.

\subsection{Structural measurement}

The casting microstructures were obtained using scanning electron microscopy. All specimens were machined from the ingots into cubes at the same position with the length, and then the specimen was rubbed, polished, and corroded by $5 \%$ Nital.

To observe the grain boundary, specimens with the size of $10 \times 10 \times 10 \mathrm{~mm}$ were heated from room temperature to $50 \mathrm{~K}$ above the austenite transformation start temperature by a vacuum heating furnace at $10 \mathrm{~K} / \mathrm{min}$. Then they were cooled down to room temperature by water-cooling. The specimen also was rubbed, polished and etched with the solution of picric acid and sodium dodecyl benzene sulfonate (SDBS) when the DSC experiment was completed. The optical microscopy was employed to study the microstructures. The linear intercept method was ap- 
plied to the size measurement of the austenite grain in the optical micrographs following the ASTM Standard E112-96 [10].

\section{Results and discussion}

\subsection{Microstructure analysis}

Fig. 1 shows the SEM morphology of the initial microstructures of the specimens in the cast condition, which predominantly consists of lamellar pearlite. Moreover, it should be noted that the lamellar microstructure of the initial pearlite changes from sparse to dense, and the average lamellar spacing of pearlite decreases from $0.34 \mu \mathrm{m}$ to $0.19 \mu \mathrm{m}$ when the Mn concentration increases.

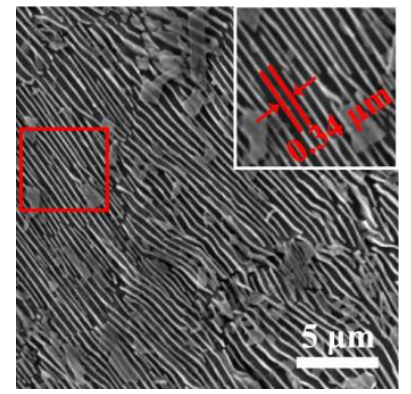

a

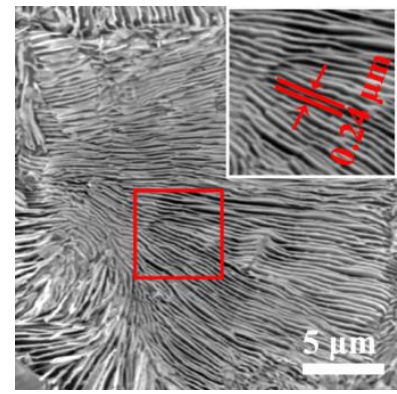

c

Fig. 1 SEM images of the specimens: $a-1 \#$; b - 2\#; $c-3 \#$; d - 4\#
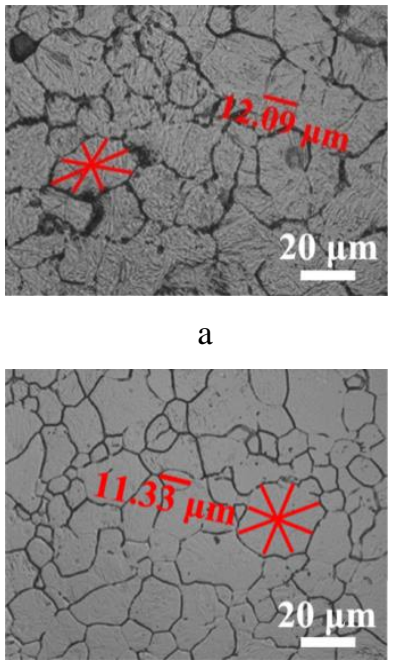

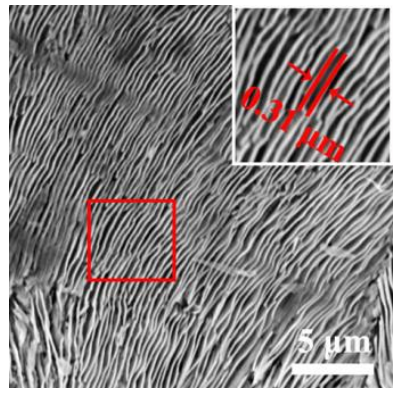

b

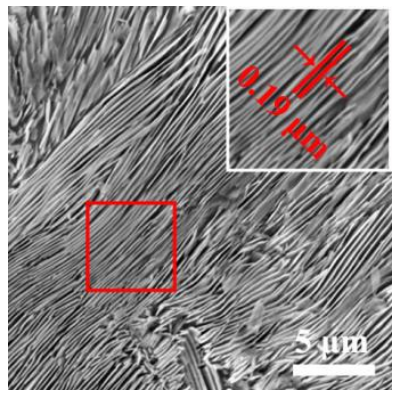

d
The OM images of the austenite grain of the specimens after the austenization process are shown in Fig. 2. The vast majority of the austenite grains are distinct and the grain boundary can be obtained clearly (the black lines on behalf of the grain boundary). Also, the average size of grains is measured. Shown as red lines in Fig. 2, each austenite grain that uses at least four different directions is measured when measuring the grain size. Then, the average value of these measurements is marked as the austenitic grain size. These measurements are plotted as histograms using Origin software and are divided into $n \approx 25$ categories. Then, the arithmetic mean grain size is fitted by the lognormal distribution in Fig. 3. The statistical of the grain size is listed in Table 2 .

As shown in Fig. 2, a, the austenite grains are inhomogeneous by distribution, the grain boundary is curving and there is a small amount of the undissolved carbide particles at the grain boundary. Those carbide particles can influence the diffusion of iron and carbon, which can result in the hindering of the growth of austenite [11-13]. With the Mn concentration up to $1.36 \mathrm{wt} \%$, there are carbides at the grain boundary and the pinning effect still exists. Moreover, according to the classical nucleation theory, there are the fluctuations of composition, microstructure and energy in the interfaces between cementite and ferrite, which is beneficial to form an austenite nucleus. Thus, the austenite nucleation will preferentially appear at the interfaces [14]. In this study, due to the addition of Mn, the lamellar spacing of pearlite is reduced, which means that more austenite nucleation sites are provided. Thus, the grain size of austenite becomes smaller. However, when the concentration of manganese is further increased, the grain boundary reduces, becoming flat and close to an angle of $120^{\circ}$. In addition, there are very small changes in the grain shape. Some of the austenite grains grow and others shrink or disappear. Furthermore, the austenite grains undergo slow coarsening, simultaneously, as seen from Fig. 2, $\mathrm{c}$ and d. Although the finer lamellar spacing of pearlite can provide more nucleation position, the austenite formation can be determined by the nucleation rate, and it is also closely related to the growth rate, which is controlled by element diffusion. As shown in Fig. 4, the austenite formation temperature is lowered and the superheat is increased as Mn concentration increases. The greater the superheat, the greater the phase transformation driving force, which is more conducive to the diffusion of the elements. This results in a faster rate of austenite formation and growth. Since Mn is a weak carbide forming element, the carbide is not stable and is more likely to dissolve at a higher superheat [15]. With the dissolution of carbide, the pinning effect disappeared. Also, it is more advantageous for the austenite grain coarsening.

Fig. 3 shows the size distribution of austenite grains after the austenization. As seen from Fig. 3, the distribution tends toward the lognormal distribution and conforms to the report by $\mathrm{Li}$ et al. [16] and Azghandi [17]. Because austenitic transformation can be assigned to the site saturation model [13], the number of the nucleation sites is maintained constant in the transformation process. The number of nucleation sites per unit volume $\left(N^{*}\right)$ is calculated by the average grain size $(d)$. Assuming that the particle-geometry factor $(g)$ is 1 [18], $N^{*}$ can be calculated as $N^{*}=1 / d^{3}$. The nucleation density is given in Table 2 .

Fig. 2 Optical micrographs of the specimens: $a-1 \#$; b - 2\#; c - 3\#; d - 4\# 
Table 2

The average austenite grain size $(d)$ and the estimated nucleus number density $\left(N^{*}\right)$ of the specimens

\begin{tabular}{|c|c|c|c|c|}
\hline & $1 \#$ & $2 \#$ & $3 \#$ & $4 \#$ \\
\hline$d, \mu \mathrm{m}$ & 12.09 & 10.82 & 11.33 & 13.06 \\
\hline$N^{*}, \mathrm{~m}^{-3} \times 10^{14}$ & 5.66 & 7.89 & 6.88 & 4.99 \\
\hline
\end{tabular}
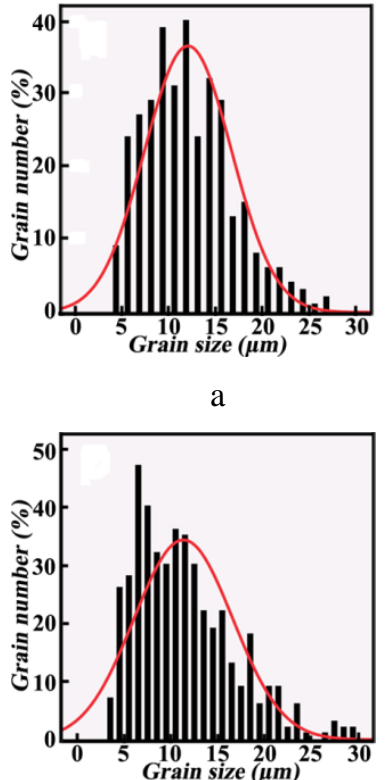

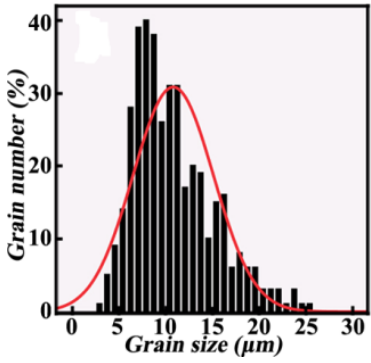

b

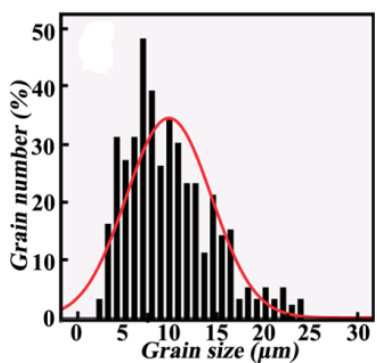

d
Fig. 3 A grain size distribution for the specimens: a - 1\#; b - 2\#; c - 3\#; d - 4\#

\subsection{DSC measurements}
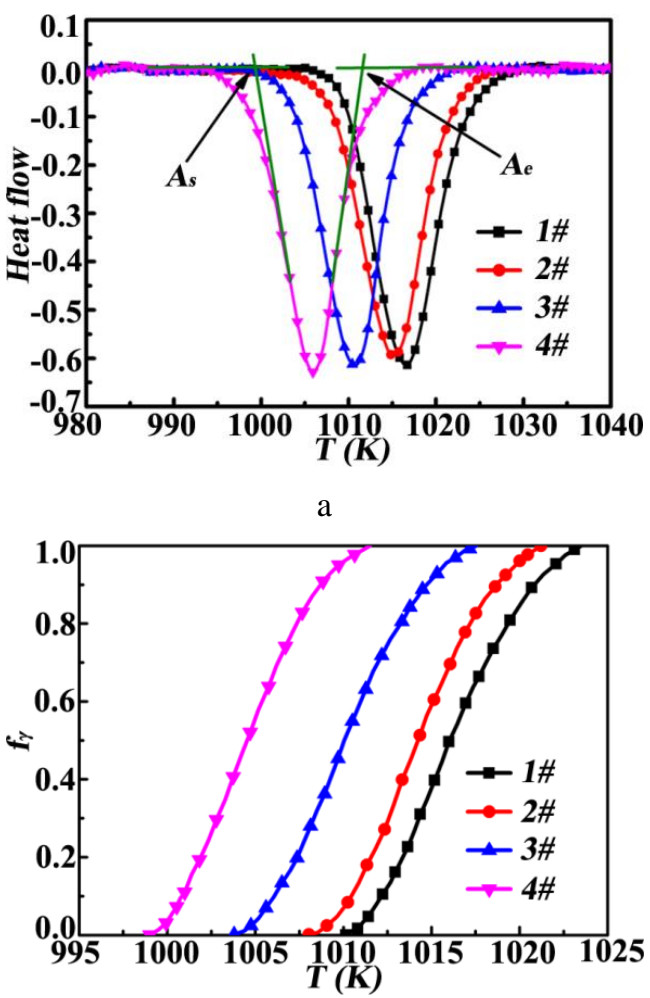

$\mathrm{b}$

Fig. 4 a-DSC curves, b-the austensitic fraction as a function of temperature calculated from DSC measurements
Fig. 4, a indicates the typical DSC curves: the endothermic peak belonging to austenite transformation is clearly observed. In addition, the austenite transformation start and end temperatures are named $A s$ and $A e$, respectively. The corresponding values of each temperature have been given in Table 3. From Fig. 4, a and Table 3, it is obvious that the endothermic peaks shift to the lower temperature as $\mathrm{Mn}$ concentration is increased from $0.99 \mathrm{wt} \%$ to $2.72 \mathrm{wt} \%$. The transformed fraction $\left(f_{\gamma}\right)$ versus temperature plots for various $\mathrm{Mn}$ concentrations are represented in Fig. 4, b for comparison with the austenization kinetics predicted by the DSC curves [19]. The observed S-shaped curves clearly indicate that the austenite transformation of each specimen has the same rate characteristics and can be attributed to the same type of phase transition [13].

Table 3

The start temperature $(A s)$ and the end temperature $(A e)$ for the transformation of the specimens $(\mathrm{K})$

\begin{tabular}{|c|c|c|c|c|}
\hline & $1 \#$ & $2 \#$ & 3\# & 4\# \\
\hline $\mathrm{As}$ & 1010.05 & 1008.01 & 1003.78 & 999.28 \\
\hline $\mathrm{Ae}$ & 1023.55 & 1021.7 & 1016.6 & 1011.31 \\
\hline
\end{tabular}

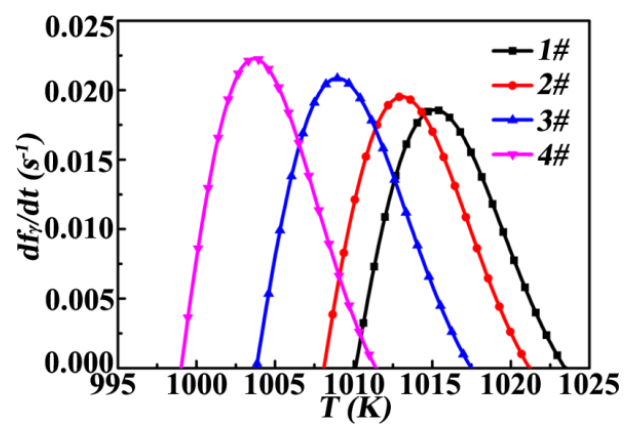

a

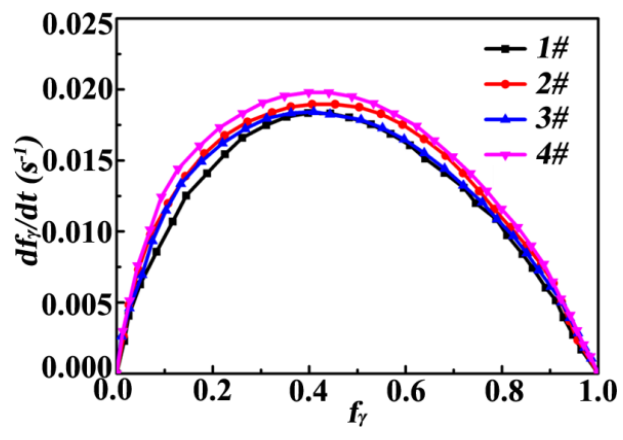

b

Fig. 5 a - Relationship between the transformation rate and temperature; $b$ - Relationship between the transformation rate and the austenite fraction

The transformation rate $d f_{\gamma} / d t$ versus temperatures and the transformed fraction, which are obtained for the different Mn concentrations, are shown in Fig. 5, a and Fig. 5, b, respectively. It is noted that each curve only has only one maximum value of the austenite formation rate. It reaffirms that the austenite transformation of specimens belongs to a normal transformation mode. As shown in Fig. 5, a, it appears that the values of $A s$ and $A e$ decrease as $\mathrm{Mn}$ concentration increases. The time of transformation also reduces slightly.

The formation process of austenite is influ- 
enced by the nucleation rate and diffusion. As shown in Fig. 1, the lamellar spacing of pearlite is reduced as Mn concentration increases, which shortens the effective diffusion distance, improves the diffusion efficiency of the element, and thereby promotes the formation of austenite. In addition, as shown in Fig. 4, a and Fig. 5, a, the start transformation temperature $(A s)$ decreases from $1010.05 \mathrm{~K}$ to 999.28 K with increasing Mn concentration. This signifies that the superheat increases. In other words, the phase transformation driving force increases. This leads to a faster austenite formation rate as Mn concentration increases.

\subsection{Kinetics}

In order to analyze the transformation kinetics, the models of nucleation, growth and the impingement correction have to be defined. According to the classical nucleation theory, the nucleation of austenite transformation is represented by the site saturation nucleation model. In the JMAK model, the nucleation rate of per unit volume, $N$, can be described as the following [20]:

$$
\stackrel{\circ}{N}=N^{*} \delta(t-0)
$$

where $\delta(t-0)$ is the Dirac function:

$$
\delta(t=0)=\left\{\begin{array}{c}
0(t \neq 0) \\
\infty(t=0)
\end{array}, \int_{-\infty}^{\infty} \delta(t-0) d t=1 .\right.
$$

Since the nucleation of austenite transformation remains with the site saturation nucleation, it can be assumed that the nucleation has been completed when the growth begins. Hence, the Dirac function is 1 , hence the following: $\stackrel{\circ}{N}=N^{*}$.

In the austenite phase transformation, the growth of the austenite grain is controlled by the diffusion of the element. In other words, the growth process of austenite can be identified with the diffusion-controlled regime. Therefore, the volume of austenite grain, $Y$, is calculated according to the following [20] :

$$
Y(t, \tau)=g\left[\int_{\tau}^{t} v(T) d t\right]^{d / m},
$$

where the geometrical factor $g$ for cubic growth, $g=1$ and for spherical growth, $g=4 \pi / 3$, the growth rate is $v(T)$, the dimensionality of growth is $d$ and the growth mode parameter is $m$. The values of $m$ and $d$ can be used to describe the type of growth: for interface-controlled and volume diffusion controlled growth, $m=1$ and $m=2$, respectively. It is well to note $d=1,2,3$ correspond to growth in one, two, or three dimensions, respectively. The growth velocity is described as:

$$
v(T)=v_{0} \exp \left(-\frac{Q_{G}}{R T}\right),
$$

where $v_{0}$ is defined as the pre-exponential factor, $Q_{G}$ is defined as the activation energy of growth and $R$ is the gas constant. Since the growth of austenite is diffusion-controlled, the pre-exponential factor and the activation energy of growth can be substituted for the pre-exponential factor $D_{0}$, as well as the activation energy of diffusion $Q_{d}$, respectively [21].

In the JMAK model, it is assumed that the impingement is random and that the austenite grain is distributed randomly and grows isotopically in the parent phase. Thus, the impingement correction can be derived as the following [22] :

$$
\frac{d f_{\gamma}}{d x_{e}}=\left(1-f_{\gamma}\right)
$$

where $x_{e}$ is defined as the extended volume fraction, that is equal to $V^{e} / V$, where $V$ is the specimen volume. After integration, this follows:

$$
f_{\gamma}=\frac{V_{t}}{V}=1-\exp \left(-\frac{V^{e}}{V}\right),
$$

where $V^{e}$ denotes the extended volume of all austenite grains.

Because the overlap between grains is ignored in calculating the volume of the grains in the nucleation and growth process, differences arise between the extended and the actual volume. Thus, the extended volume must be corrected. It can be described as [22]:

$$
V^{e}=\int_{0}^{t} V \stackrel{\circ}{N} Y(t, \tau) d \tau
$$

According to Eqs. (1)-(3) and Eq. (6), the extended volume can be calculated as:

$$
\begin{aligned}
& V^{e}=\int_{T_{0}}^{T(t)} V N^{*} \delta\left[\frac{T(\tau)-T_{0}}{\Phi}\right] g \times \\
& \times\left[\int_{T(\tau)}^{T(t)} D_{0} \exp \left(-\frac{Q_{d}}{R T}\right) d \frac{T}{\Phi}\right]^{3 / 2} d \frac{T(\tau)}{\Phi},
\end{aligned}
$$

where $\Phi$ is the heating rate. An approximate method involving series expansion and integration is used in order to avoid the error caused by the temperature integral. The approximate expression is as follows [23]:

$$
\begin{aligned}
& \int_{T(\tau)}^{T(t)} \exp \left(-\frac{Q_{d}}{R T}\right) d T \approx \exp \left[-\frac{Q_{d}}{R T(t)}\right] \int_{T(\tau)}^{T(t)} \exp \left\{\frac{Q_{d}[T-T(t)]}{R T(t)^{2}}\right\} d T= \\
& =\exp \left[-\frac{Q_{d}}{R T(t)}\right] \frac{R T(t)^{2}}{Q_{d}}\left\langle 1-\exp \left\{\frac{Q_{d}[T(\tau)-T(t)]}{R T(t)^{2}}\right\}\right\rangle .
\end{aligned}
$$


On the basis of Eqs. (8)-(7) can be written as:

$$
V^{e}=V N^{*} g\left(\frac{D_{0}}{\Phi}\right)^{3 / 2} \times\left\langle\exp \left[-\frac{Q_{d}}{R T(t)}\right] \frac{R T(t)^{2}}{Q_{d}}\left\langle 1-\exp \left\{\frac{Q_{d}\left[T_{0}-T(t)\right]}{R T(t)^{2}}\right\}\right\rangle\right\rangle^{3 / 2}
$$

The austenite fraction can be attained by combining Eq. (5) with Eq. (8):

$$
f_{\gamma}=1-\exp \left\langle-N^{*} g\left(\frac{D_{0}}{\Phi}\right)^{3 / 2}\left\langle\exp \left[-\frac{Q_{d}}{R T(t)}\right] \frac{R T(t)^{2}}{Q_{d}}\left\langle 1-\exp \left\{\frac{Q_{d}\left[T_{0}-T(t)\right]}{R T(t)^{2}}\right\}\right\rangle\right\rangle^{3 / 2}\right\rangle
$$

Using the modified JMAK model, the experimental results are correlated and the values of $D_{0}$ and $Q_{d}$ are obtained. The experimental and fitted curves obtained are shown in Fig. 6. It is found that the experimental results are consistent with the plots. The values of $D_{0}$ and $Q_{d}$ are listed in Table 4.

Table 4

Diffusion parameters determined for four specimens using the phase-transformation model

\begin{tabular}{|c|c|c|c|c|}
\hline & $1 \#$ & $2 \#$ & $3 \#$ & 4\# \\
\hline$Q_{d}\left(\mathrm{~kJ} \mathrm{~mol}^{-1}\right)$ & 178.81 & 178.35 & 176.32 & 169.83 \\
\hline $\begin{array}{c}D_{0}\left(\mathrm{~m}^{2} \mathrm{~s}^{-1}\right) \\
\times 10^{-3}\end{array}$ & 5.32 & 4.16 & 3.74 & 3.1 \\
\hline
\end{tabular}

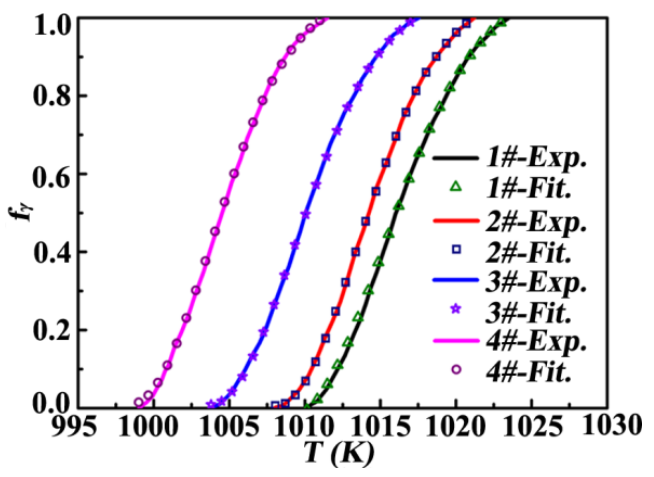

a

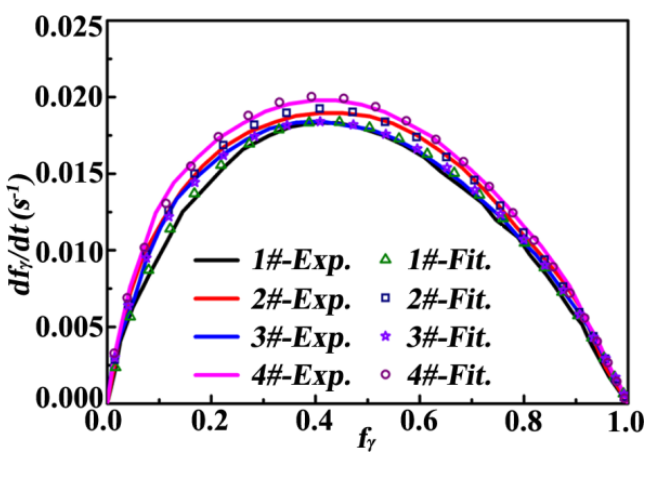

b

Fig. 6 Comparison between measured values and calculated values: a - the relationship between the austenite fraction and temperature; $b$ - the relationship between the formation rate and the austenite fraction

The formation of austenite depends on the diffu- sion. The diffusion is affected by the external conditions, such as heat, pressure and stress, as well as internal factors, such as microstructure and chemical composition. The activation energy of diffusion is one of the important parameters, as it reflects the diffusion, which represents the necessary energy to go over the energy barrier during the movement of the atom from one equilibrium position to another equilibrium position. The activation energy of diffusion is a measure of the difficulty in the phase transformation; the smaller the diffusion activation energy, the more favorable it is for the phase transformation, and vice versa.

In this study, the average lamellar spacing of pearlite decreases from $0.34 \mu \mathrm{m}$ to $0.19 \mu \mathrm{m}$ when $\mathrm{Mn}$ concentration increases. This means that the interfaces between the ferrite and cementite are also increased. Fluctuations that occur in the structure, energy and concentration in the interfaces will lead to distortion and high energy. The increase of defects causes the reduction of the activation energy of diffusion of the phase transition. Thus, as shown in Table 4, the activation energy of diffusion becomes smaller from $178.81 \mathrm{~kJ} \mathrm{~mol}^{-1}$ to $169.83 \mathrm{~kJ} \mathrm{~mol}^{-1}$ as Mn concentration increases.

In regards to the pre-exponential factor, with the increase in Mo concentration, the introduction of Mn narrows the lamellar spacing of pearlite. The finer pearlite microstructure not only brings more nucleation sites, but also shortens the effective diffusion distance. Therefore, the changes of microstructure caused by the addition of $\mathrm{Mn}$ are favorable for the nucleation of austenite and for the diffusion in austenite. However, the start temperature of the phase transition is reduced, the lower temperature reduces the velocity of the element diffusion. In addition, Mn as a carbide-forming element, the larger number of $\mathrm{Mn}$ reduces the concentration of carbon in austenite. It is also not conducive to the diffusion of the elements. As mentioned above, under the function of two conflicting factors, the pre-exponential factor decreases from $5.32 \times 10^{-3} \mathrm{~m}^{2} \mathrm{~s}^{-1}$ to $3.1 \times 10^{-3} \mathrm{~m}^{2} \mathrm{~s}^{-1}$.

\section{Conclusions}

In summary, the influence of $\mathrm{Mn}$ on the microstructure and the kinetics of the austenite phase transformation in the Fe-Mn-C ternary alloys are investigated. The comparison of experimental curves and the modified JMAK model results demonstrate that the start temperature of austenization is reduced from $1010.05 \mathrm{~K}$ to $999.28 \mathrm{~K}$. Also, it shows that the austenite formation rate is increased with an increase in Mn concentration. This is caused by the 
smaller lamellar spacing of pearlite due to the Mn addition in the as-cast state. Consequently, the effective diffusion distance is decreased and the number of the austenite nucleation sites is increased. Moreover, the finer pearlite microstructure and the greater superheat that led to the activation energy of diffusion became smaller from $178.81 \mathrm{~kJ} \mathrm{~mol}^{-1}$ to $169.83 \mathrm{~kJ} \mathrm{~mol}^{-1}$, and the pre-exponential factor decreases from $5.32 \times 10^{-3} \mathrm{~m}^{2} \mathrm{~s}^{-1}$ to $3.1 \times 10^{-3} \mathrm{~m}^{2} \mathrm{~s}^{-1}$.

\section{Acknowledgements}

This work is supported by the National Natural Science Foundation of China (Grant No.51201068, No, 50901035), the Science and Technology Development Projects of Jilin Province (Grant No. 20130301006GX, No. 20140101051JC and No. 20130204017GX).

\section{References}

1. Zhang, L.; Song, R.; Zhao, C. et al. 2015. Evolution of the microstructure and mechanical properties of an austenite-ferrite Fe-Mn-Al-C steel, Materials Science \& Engineering A 643: 183-193.

http://dx.doi.org/10.1016/j.msea.2015.07.043.

2. Jabłońska, M.; Kuc, D.; Niewielski, G. et al. 2015. Influence of the thermo-mechanical treatment on the properties and microstructure of high manganese austenitic-ferritic steel, Solid State Phenomena 226: 75-78.

http://dx.doi.org/10.4028/www.scientific.net/SSP.226.7 5 .

3. Kumar, A.; Sharma, A.; Goel, S.K. 2015. Effect of heat treatment on microstructure, mechanical properties and erosion resistance of cast 23-8-N nitronic steel, Materials Science \& Engineering A 637: 56-62. http://dx.doi.org/10.1016/j.msea.2015.04.031.

4. Liang, Z.; Sha W.; Zhao Q. et al. 2016. The Effect of Aging Heat Treatment on the Microstructure and Mechanical Properties of 10Cr20Ni25Mo1.5NbN Austenitic Steel, High Temperature Materials \& Processes 35: 1-7. http://dx.doi.org/10.1016/j.msea.2015.04.031.

5. Ivashko, A.G.; Tsyganova, M.S.; Nabatov, R.I. 2016. Decomposition kinetics of supercooled austenite in porous powder steel, Steel in Translation 46: 196-200. http://dx.doi.org/10.3103/S0967091216030062.

6. Shirdel, M.; Mirzadeh, H.; Parsa, M.H. 2015. Estimation of the kinetics of martensitic transformation in austenitic stainless steels by conventional and novel approaches, Materials Science \& Engineering A 624: 256-260.

http://dx.doi.org/10.1016/j.msea.2014.11.087.

7. Chastukhin, A.V.; Ringinen, D.A.; Khadeev, G.E. et al. 2016. Kinetics of the static recrystallization of austenite in niobium-microalloyed pipe steels, Metallurgist 59: 1180-1187. http://dx.doi.org/10.1007/s11015-016-0234-6.

8. Zhang, G.H.; Chae, J.Y.; Kim, K.H. et al. 2013. Effects of $\mathrm{Mn}, \mathrm{Si}$ and $\mathrm{Cr}$ addition on the dissolution and coarsening of pearlitic cementite during intercritical austenitization in Fe-1mass \%C alloy, Mater. Charact. 81: 56-67. http://dx.doi.org/10.1016/j.matchar.2013.04.007.

9. Sharma, S.; Nanda, T.; Adhikary, M. et al. 2016. A simulation study of pearlite-to-austenite transformation kinetics in rapidly heated hot-rolled low carbon steel, Materials \& Design 107: 65-73.

http://dx.doi.org/10.1016/j.matdes.2016.06.025.

10. Bhattacharyya, J.; Agnew, S.; Muralidharan, G. 2015. Texture evolution during grain growth of magnesium alloy AZ31B, Acta Mater. 86: 80-94.

http://dx.doi.org/10.1016/j.actamat.2014.12.009.

11. Calcagnotto, M.; Ponge, D.; Raabe, D. 2014. On the effect of manganese on grain size stability and hardenability in ultrafine-grained ferrite/martensite dual-phase steels, Metallurgical \& Materials Transactions A 43A: 37-46. http://dx.doi.org/10.1007/s11661-011-0828-3.

12. Pierce, D.T.; Coughlin, D.R.; Williamson, D.L. et al. 2016. Quantitative investigation into the influence of temperature on carbide and austenite evolution during partitioning of a quenched and partitioned steel, Scr. Mater. 121: 5-9.

http://dx.doi.org/10.1016/j.scriptamat.2016.04.027.

13. Kong, L.N.; Liu, Y.H.; Liu, J.A. et al. 2015. The influence of chromium on the pearlite-austenite transformation kinetics of the $\mathrm{Fe}-\mathrm{Cr}-\mathrm{C}$ ternary steels, J. Alloys Compd. 648: 494-499. http://dx.doi.org/10.1016/j.jallcom.2015.06.259.

14. Chen, L.; Zhang, J.; Tian, Y. et al. 2015. Austenite morphology feature and nucleation mechanism during intercritical reheating of martensite steel, Jinshu Rechuli/heat Treatment of Metals 40: 68-72. http://dx.doi.org/10.13251/j.issn.0254-6051.2015.08.01 3.

15. Luo, H.W.; Qiu, C.H.; Dong, H. et al. 2014. Experimental and numerical analysis of influence of carbide on austenitisation kinetics in 5Mn TRIP steel, Materials Science \& Technology 30: 1367-1377. http://dx.doi.org/10.1179/1743284713Y.0000000447.

16. Li, Z.; Wen, Z.; Su, F. et al. 2016. Austenite grain growth behavior of a $\mathrm{GCr} 15$ bearing steel cast billet in the homogenization heat treatment process, J. Mater. Res. 31: 2105-2113. http://dx.doi.org/10.1557/jmr.2016.248.

17. Azghandi, S.H.M.; Ahmadabadi, V.G.; Zabett, A. et al. 2014. Modelling of austenite grain growth kinetics in a microalloyed steel (30MSV6) in the presence of carbonitride precipitates, Philos. Mag. 94: 2758-2775. http://dx.doi.org/10.1080/14786435.2014.932460.

18. Hong, S.C.; Lim, S.H.; Hong, H.S. et al. 2003. Effects of $\mathrm{Nb}$ on strain induced ferrite transformation in $\mathrm{C}-\mathrm{Mn}$ steel, Materials Science and Engineering: A 355: 241-248. http://dx.doi.org/10.1016/S0921-5093(03)00071-6.

19. Wang, Y.T.; Yuan, X.G.; Yu, B.Y. et al. 2014. Numerical analysis of liquid fraction in solid-liquid phase transformation of semisolid alloy, Materials Science \& Technology 30: 1399-1403. http://dx.doi.org/10.1179/1743284713Y.0000000464.

20. Liu, Y.C.; Wang, D.; Sommer, F. et al. 2008. Isothermal austenite-ferrite transformation of $\mathrm{Fe}-0.04$ at.\% C alloy: Dilatometric measurement and kinetic analysis, Acta Mater. 56: 3833-3842. http://dx.doi.org/10.1016/j.actamat.2008.04.015.

21. Ma, Q.; Shao, Y.; Liu, Y.C. et al. 2013. Martensite-austenite transformation kinetics of high $\mathrm{Cr}$ ferritic heat-resistant steel, Int. J. Mater. Res. 
104: 935-940.

http://dx.doi.org/10.3139/146.110951.

22. Jiang, Y.H.; Liu, F.; Song, S.J. et al. 2013. Evaluation of the maximum transformation rate for determination of impingement mode upon near-equilibrium solid-state phase transformation, Thermochimica Acta 561: 54-62.

http://dx.doi.org/10.1016/j.tca.2013.03.023.

23. Gao, Q.; Wang, C.; Qu, F. et al. 2014. Martensite transformation kinetics in $9 \mathrm{Cr}-1.7 \mathrm{~W}-0.4 \mathrm{Mo}-\mathrm{Co}$ ferritic steel, Journal of Alloys \& Compounds 610: 322-330.

http://dx.doi.org/10.1016/j.jallcom.2014.05.060.

Lingnan Kong, Yaohui Liu, Yulai Song, Jia'an Liu,

Shasha Li, Yan Liang, Yi Zheng, Wei Cui

THE INFLUENCE OF MANGANESE ON KINETICS OF AUSTENITIZATION OF THE Fe-Mn-C TERNARY ALLOYS

S u m m a r y

The influence of manganese on the microstructure and kinetics of the austenization in the Fe-Mn-C ternary alloys, which contains four grades of Mn concentration, is studied under continuous heating. The transformation of the pearlite-austenite has been measured by differential scanning calorimetry (DSC) in temperatures that ranged from room temperature to $1373 \mathrm{~K}$. Also, the microstructure of the as-cast and the completion of the DSC test is obtained using optical microscopy (OM) and scanning electron microscopy (SEM), respectively. The analysis of the microstructure indicates that the lamellar spacing of the initial pearlite is refined from $0.34 \mu \mathrm{m}$ to $0.19 \mu \mathrm{m}$. It also indicates that austenite grain coarsening occurs as $\mathrm{Mn}$ concentration increases. The comparison of experimental kinetic curves and the Johnson-Mehl-Avrami-Kolmogorov model (JMAK) shows that the start temperature of austenization is decreased from $1010.5 \mathrm{~K}$ to $999.28 \mathrm{~K}$. and that the austenite formation rate is accelerated. Moreover, the activation energy of diffusion decreases from $192.88 \mathrm{~kJ} \mathrm{~mol}^{-1}$ to $178.47 \mathrm{~kJ} \mathrm{~mol}^{-1}$, and the pre-exponential factor decreases from $5.32 \times 10^{-3} \mathrm{~m}^{2} \mathrm{~s}^{-1}$ to $3.1 \times 10^{-3} \mathrm{~m}^{2} \mathrm{~s}^{-1}$.

Keywords: pearlite; austenization; kinetics; the JMAK model; Fe-Mn-C ternary alloys.

Received October 14, 2016

Accepted April 14, 2017 